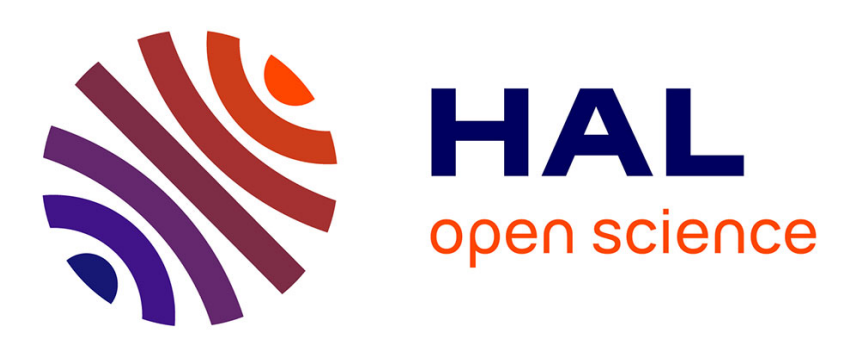

\title{
High temperature superconducting axial field magnetic coupler: realization and test
}

Lamia Belguerras, Smail Mezani, Thierry Lubin, Jean Lévêque, Abderrezak Rezzoug

\section{- To cite this version:}

Lamia Belguerras, Smail Mezani, Thierry Lubin, Jean Lévêque, Abderrezak Rezzoug. High temperature superconducting axial field magnetic coupler: realization and test. Superconductor Science and Technology, 2015, 28 (9), 20 p. 10.1088/0953-2048/28/9/095003 . hal-01164395

\section{HAL Id: hal-01164395 \\ https://hal.science/hal-01164395}

Submitted on 16 Jun 2015

HAL is a multi-disciplinary open access archive for the deposit and dissemination of scientific research documents, whether they are published or not. The documents may come from teaching and research institutions in France or abroad, or from public or private research centers.
L'archive ouverte pluridisciplinaire HAL, est destinée au dépôt et à la diffusion de documents scientifiques de niveau recherche, publiés ou non, émanant des établissements d'enseignement et de recherche français ou étrangers, des laboratoires publics ou privés. 


\title{
HIGH TEMPERATURE SUPERCONDUCTING AXIAL FIELD MAGNETIC COUPLER: REALIZATION AND TEST
}

\author{
L. Belguerras, S. Mezani, T. Lubin, J. Lévêque, and A. Rezzoug \\ Université de Lorraine, Faculté des Sciences et Technologies, Laboratoire GREEN \\ BP 70239, 54506, Vandœuvre-lès-Nancy, France
}

\begin{abstract}
Contactless torque transmission through a large airgap is required in some industrial applications in which hermetic isolation is necessary. This torque transmission usually uses magnetic couplers, whose dimension strongly depends on the airgap flux density. The use of High Temperature Superconducting (HTS) coils to create a strong magnetic field may constitute a solution to reduce the size of the coupler. It is also possible to use this coupler to replace a torque tube in transmitting the torque produced by a HTS motor to its load. This paper presents the detailed construction and tests of an axial field HTS magnetic coupler. Pancake coils have been manufactured from BSCCO tape and used in one rotor of the coupler. The second rotor is mainly composed of $\mathrm{NdFeB}$ permanent magnets. Several tests have been carried out showing that the constructed coupler is working properly. A 3D finite element (FE) model of the studied coupler has been developed. Airgap magnetic field and torque measurements have been carried out and compared to the FE results. It has been shown that the measured and the computed quantities are in satisfactory agreement.
\end{abstract}

Keywords: Magnetic couplers, HTS coils, BSCCO tapes, permanent magnets, 3D finite elements.

\section{Introduction}

Magnetic Couplings (or couplers) (MCs) are used to transmit a torque from a prime mover to its load without contact through a separation wall which can be air, vacuum, fluid or other media [1]. Compared to their mechanical counterpart, magnetic couplers have several advantages like low mechanical vibrations, less wear, natural protection against overloads and permit misalignment. Furthermore, they can allow for a hermetic isolation between the drive and the load sides by means of a separation wall, which is of great importance in some industrial applications (i.e. nuclear, chemical, pharmaceutical and food industries).

Incorporating a wall can lead to a large magnetic air gap which results in low transmitted electromagnetic torque. To increase the torque transmitted through a large airgap, High Temperature Superconducting (HTS) materials can be used. In so doing, high current values are achievable in HTS winding which results in strong magnetic fields in the airgap. These materials have been used in several types of electromechanical devices like motors and generators showing their usefulness in increasing 
the power and torque densities [2,3]. Furthermore, superconducting MCs can be used to transmit the torque produced by a HTS motor. In [4], a flux concentration superconducting MC has been proposed for high power HTS motors requiring high torque density. The proposed solution constitutes a good alternative to a torque tube usually used to mechanically link the HTS motors and its load [5]. A torque tube is made from fiber glass to ensure the lowest possible thermal bridge between the motor (at cryogenic temperature) and the load (at ambient temperature). Despite the precautions taken to build a torque tube (in terms of material grade, geometry...), the thermal insulation is not perfect which may lead to high cost cooling systems.

In this paper, the authors describe the construction and the tests of an HTS Axial Flux Superconducting Magnetic Coupler (AFSMC). The aim is to transmit the torque without contact and without thermal exchange through a large air-gap. 3D finite element (FE) computations are performed to determine the operating conditions, to predict the magnetic field distribution in the airgap and to check the measured torque of the coupler.

\section{Description of the studied AFSMC}

To verify the relevance of the proposed idea, we designed and constructed an AFSMC demonstrator within the prototyping capabilities of our Laboratory.

The considered coupler has two cylindrical rotors facing each other and separated by the wall of the cryostat (Figure 1.a).

The first rotor is composed of axially magnetized cylindrical permanent magnets (PM) glued on the surface of a ferromagnetic yoke. Each of the four magnets has an opposite polarity compared to its neighbouring ones to create a spatially variable magnetic field in the airgap.

The second rotor consists of HTS pancake coils mounted on a ferromagnetic yoke and cooled with liquid nitrogen $(77 \mathrm{~K})$ in a cryostat. The four coils are supplied by a dc current to create alternate north-south poles (like the PMs) in the airgap. For a more convenient and economic usage of the liquid nitrogen, the prototype is disposed vertically.

\subsection{Geometrical constraints}

The magnet and the HTS coil have the same external radius noted $\mathrm{R}_{\mathrm{be}}$. Let us consider one pole among the $2 p$ poles of the studied coupler (HTS rotor in Figure 1.b). The centre of the coil (or the magnet) is located at a radius noted $R_{\text {mean }}$ which is calculated by 


$$
R_{\text {mean }}=\beta \frac{R_{b e}}{\sin \left(\frac{\pi}{2 p}\right)} \quad \beta>1
$$

The value $\beta=1$ corresponds to a coil (or a magnet) spanning the whole pole opening angle (as in Figure 1.b). Hence, the lowest value of the external radius of the coupler is $R_{e}=R_{\text {mean }}+R_{b e}$ and the highest inner radius is $R_{i}=R_{\text {mean }}-R_{b e}$. Furthermore, relation (1) shows that, for a given value of $R_{b e}$, the outer radius $R_{e}$ increases with p. Hence, in order to keep the coupler within reasonable dimensions, the number of pole pairs has been set to $\mathrm{p}=2$ (as in Figure 1.a).

Another constraint concerns the inner radius of the HTS coil whose minimum value $\mathrm{R}_{b i}$ should be higher than the critical bending radius of the HTS wire (see section 3.1).

The aforementioned considerations are important for a preliminary geometrical design of the AFSMC.

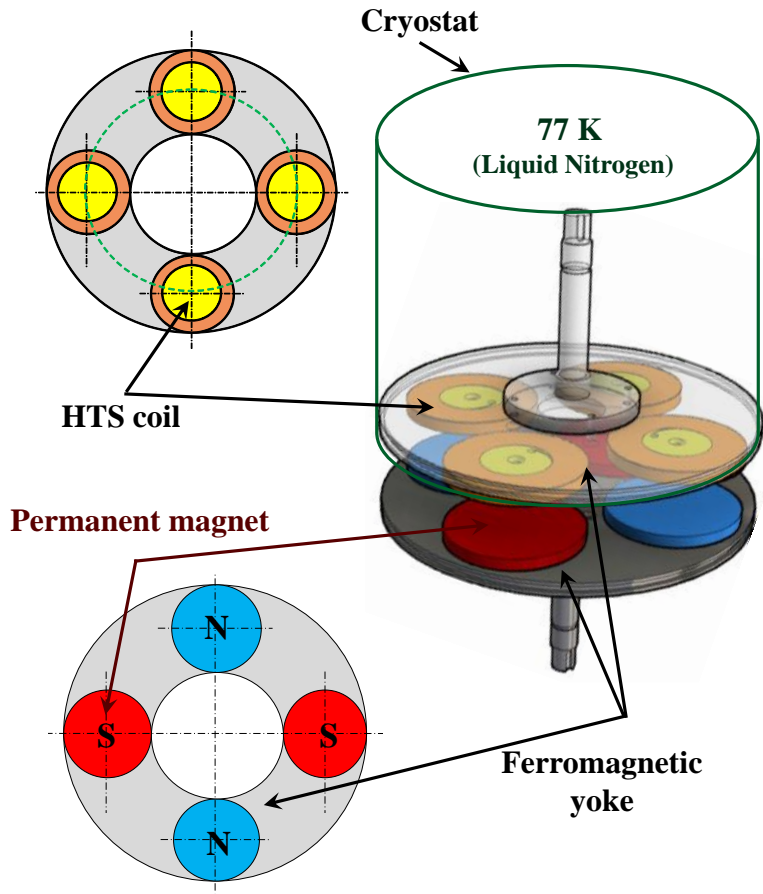

(a)

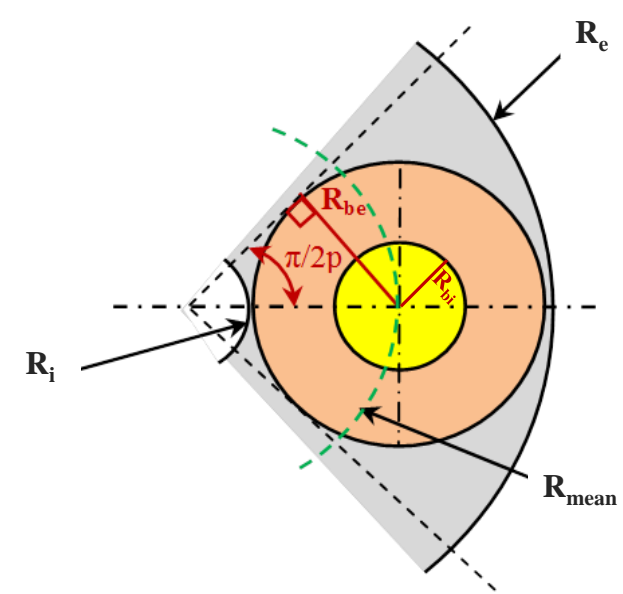

(b)

Figure 1 Structure of the studied AFSMC

(a) Different parts of the AFSMC (b) 2D geometry under 1 pole of the HTS rotor 


\section{Construction of the AFSMC}

An AFSMC laboratory demonstrator has been built and tested. This demonstrator doesn't fulfil any constraint regarding the torque transmission capabilities. The aim here is to show the feasibility of the device and to learn more about the HTS material behaviour and performances when they are used in the proposed coupling topology.

\subsection{The HTS rotor}

We have manufactured four single pancake coils (4 poles) made from non-insulated BSCCO/Ag (Bismuth Strontium Calcium Copper Oxide) multi-filamentary tape manufactured by Sumitomo electric (ACT type) [6]. The dimensions of the tape are $\mathrm{w}=2.8 \mathrm{~mm}$ width and $\mathrm{h}=0.33 \mathrm{~mm}$ thickness. Its critical current under self-field at liquid nitrogen temperature $(77 \mathrm{~K})$ is $70 \mathrm{~A}(1 \mu \mathrm{V} / \mathrm{cm}$ critical electric field criterion). The critical bending diameter of the tape is $40 \mathrm{~mm}$. Each coil has an outer radius $R_{b e}=50 \mathrm{~mm}$ and an inner radius $\mathrm{R}_{\mathrm{bi}}=25 \mathrm{~mm}$. This requires $14.8 \mathrm{~m}$ of $\mathrm{BSCCO}$ tape which results in 63 turns. During the winding process, the tape was insulated by means of a Kapton film. After being wound, each coil was impregnated using epoxy resin (Araldite AY 103-1).

In order to supply and to check the integrity of the HTS coils, two current leads and two voltage taps have been soldered on the coil's terminals (Figure 2). This allows the measurements of the voltagecurrent curve of the coils using the 4-wires method.

According to equation (1) with $R_{b e}=50 \mathrm{~mm}$, the resulting mean radius of the coupler is $R_{\text {mean }}=85 \mathrm{~mm}$ for $\beta=1.2$. This value of $\beta$ has been chosen to simplify the assembly of the coils and the magnets on the iron yokes. The inner and outer radii of the AFSMC would then be equal to $R_{i}=35 \mathrm{~mm}$ and $R_{\mathrm{e}}=135 \mathrm{~mm}$, respectively. However, the iron yoke (E24 grade mild steel) on which the coils are bolt is slightly bigger in order to facilitate the rotor assembly into the cryostat base. The main dimensions of the HTS rotor are summarized in Table 1. The coils have been connected in series to form four alternating poles (Figure $3)$. 
Table 1 Parameters of the HTS rotor

\begin{tabular}{|l|l|c|}
\cline { 2 - 3 } \multicolumn{1}{c|}{} & Quantity & Value \\
\hline & Tape critical current at 77K & $70 \mathrm{~A}$ \\
BSCCO Coil & Outer radius & $50 \mathrm{~mm}$ \\
(Sumitomo ACT type) & Inner radius & $25 \mathrm{~mm}$ \\
& Thickness (1 insulated layer) & $3.5 \mathrm{~mm}$ \\
& Number of turns & 63 \\
\hline \multirow{2}{*}{ Ferromagnetic yoke } & Outer radius & $152 \mathrm{~mm}$ \\
(E24 grade mild steel) & Inner radius & $25 \mathrm{~mm}$ \\
& Thickness & $10 \mathrm{~mm}$ \\
\hline
\end{tabular}

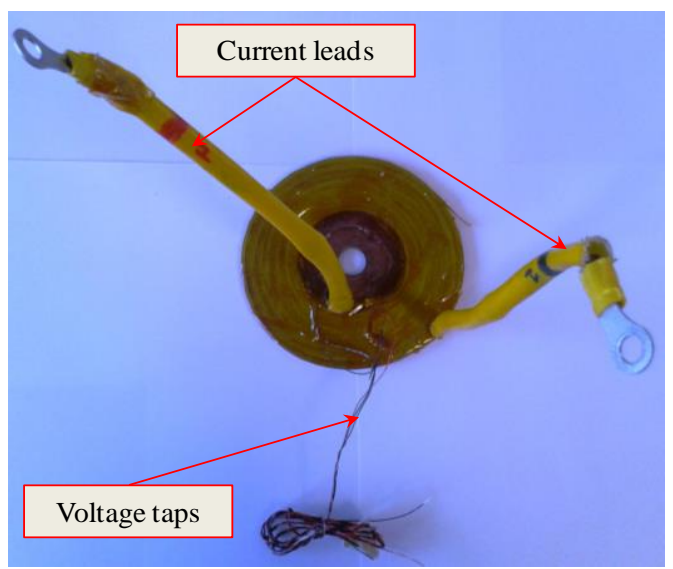

Figure 2 Photograph of the manufactured BSSCO coil

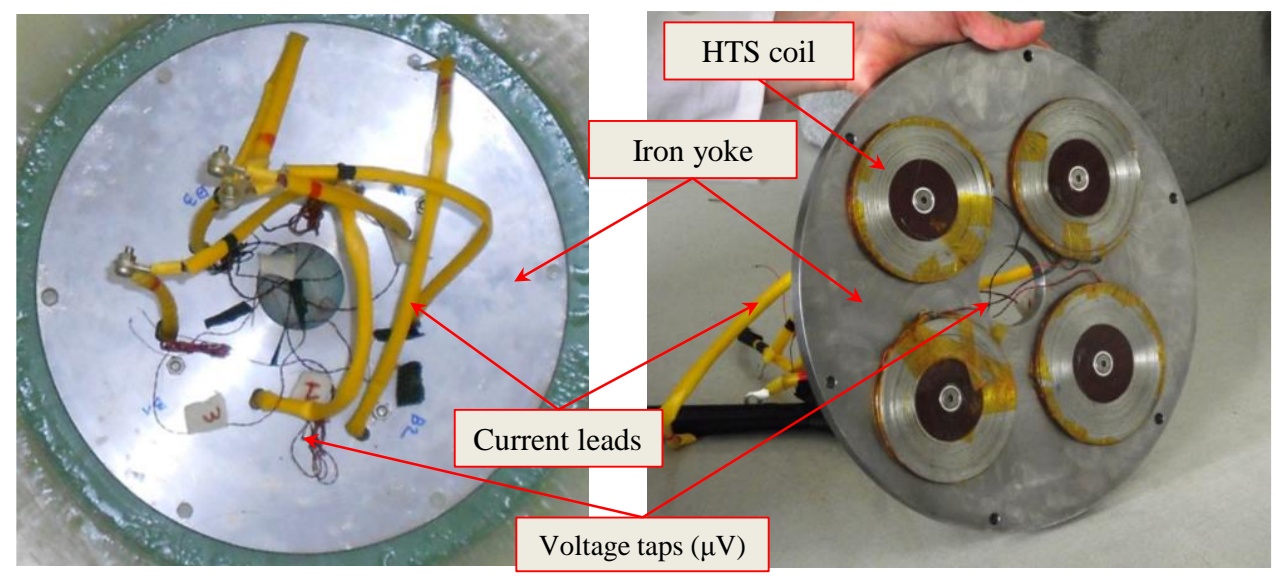

(a)

(b)

Figure 3 Photograph of the HTS rotor showing the coils bolt on the iron yoke (a) Top view showing connection of the HTS coils (b) Bottom view showing HTS coils 


\subsection{The permanent magnets rotor}

The permanent magnet rotor is composed of four cylindrical, axially magnetized, NdFeB magnets. Their remanent flux density is equal to $1.25 \mathrm{~T}$ and their relative permeability is equal to 1.05 . The magnets have been stuck on the surface of a ferromagnetic yoke (E24 grade mild steel) as to create four alternate poles (Figure 4). These large magnets are mechanically fragile and must be handled with care during the gluing process. The main characteristics of the PMs rotor are given in Table 2.

\subsection{The cryostat}

A cryostat made of glass fiber (G11 grade) has been also manufactured. It consists of two separate parts: the base and the top.

The cryostat base, of 3mm thickness, and the HTS rotor are mechanically assembled as shown on (Figure 5.a). A circular groove has also been machined at the periphery of the cryostat base. Hence, a cylindrical glass fiber tube of $10 \mathrm{~mm}$ thickness (top of the cryostat) has been easily inserted in the groove, glued and sealed. The full assembled cryostat is shown in Figure 5..b. Furthermore, (see Figure 16), an extra cover ensures a better insulation of the cryostat as to limit the liquid nitrogen consumption.

Table 2 Parameters of the PMs rotor

\begin{tabular}{|c|l|c|}
\cline { 2 - 3 } \multicolumn{1}{c|}{} & Quantity & Value \\
\hline \multirow{4}{*}{ Cylindrical PM } & Radius & $50 \mathrm{~mm}$ \\
(NdFeB, N38 grade) & Thickness & $10 \mathrm{~mm}$ \\
& Remanence & $1.25 \mathrm{~T}$ \\
& Relative permeability & 1.05 \\
\hline \multirow{2}{*}{ Ferromagnetic yoke } & Outer radius & $140 \mathrm{~mm}$ \\
(E24 grade mild steel) & Inner radius & $34.5 \mathrm{~mm}$ \\
& Thickness & $10 \mathrm{~mm}$ \\
\hline
\end{tabular}




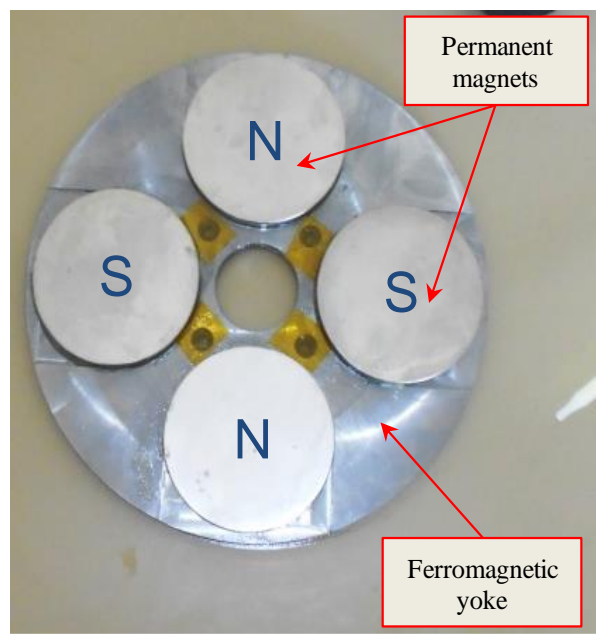

Figure 4 Photograph of the assembled permanent magnets rotor

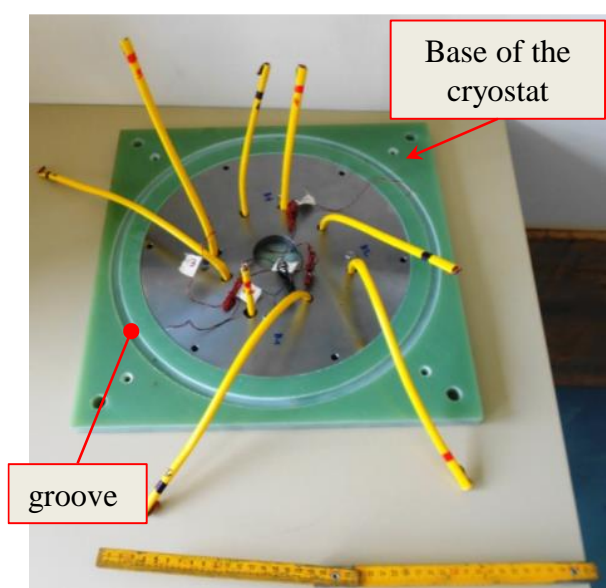

(a)

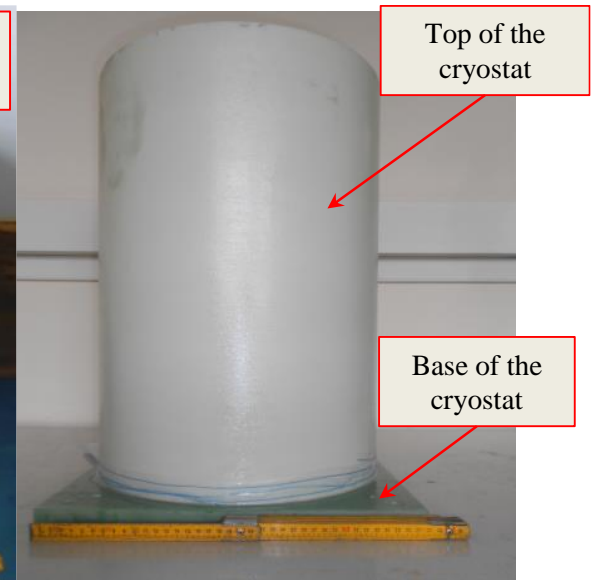

(b)

Figure 5. Photographs of the glass fiber cryostat (a) cryostat base containing the HTS rotor (b) external view of the assembled cryostat

\section{Test results and finite element checking}

This section is devoted to the presentation of different test results performed on the demonstrator AFSMC. All the measurements have been carried out under static operation. Both PMs and HTS rotors are held stationary with a fixed load angle $\delta$ between their poles.

In order to confirm the measured characteristics and to design this type of coupler, 3D finite elements (FE) computations have also been performed. The FE model is implemented under Comsol Multiphysics software (4.2 release). The "no current" module which uses a magnetic scalar potential formulation has been used. In so doing, the pancake coils currents have been replaced by an equivalent Coulombian model (equivalent magnetization). Due to the symmetry of the coupler, only 1 pole is considered with anti-periodic boundary conditions in the azimuthal direction. Because of the large magnetic airgap 
(cryostat wall, PMs and coil thicknesses), the flux density is low enough to neglect the saturation of the two iron yokes. Hence, a linear model with a relative permeability value equals to 1000 is used for the ferromagnetic materials.

As stated above, the 3D FE model allows the computation of the magnetic scalar potential $\mathrm{V}_{\mathrm{m}}$. Then, the magnetic field strength is deduced using $\vec{H}=-\nabla V_{m}$ and the flux density $\vec{B}$ is obtained via the material's constitutive laws. The determination of $\vec{B}$ and $\vec{H}$ allow the computation of the torque and the force using the Maxwell stress tensor. All these computed qunatities (obtained from built-in functions in Comsol Multiphysics) are used here in order to confirm the measured characteristics on the constructed AFSMC.

\subsection{Test of each HTS coil under its self-field condition}

In order to verify the integrity of the manufactured coils, their voltage-current $\mathrm{U}(\mathrm{I})$ curves have been measured using the four-wire method.

The experimental procedure (Figure 6) consists of supplying the HTS coil (via the current leads), immerged in liquid nitrogen, using a dc current source. The voltage over the coil's terminals is measured via the voltage taps with a digital nanovoltmeter. Then, one can deduce the critical current of the coil which corresponds to the intersection of the $\mathrm{U}(\mathrm{I})$ curve with the critical voltage line [7,8]. The total tape length for each coil being equal to $14.8 \mathrm{~m}$, the critical voltage over the coil's terminals is then equal to $1.48 \mathrm{mV}$ (the usual electric field criteria of $1 \mu \mathrm{V} / \mathrm{cm}$ is assumed).

The measured U(I) curve for the four manufactured coils are presented in Figure 7. It can be seen that the $\mathrm{U}(\mathrm{I})$ curves are almost the same. The critical currents of the four coils are equal to $44 \mathrm{~A}, 44 \mathrm{~A}, 43.8$ A and 43.7 A, respectively. The average value of the critical current of the tested HTS coils is 43.9 A, which corresponds to $62.8 \%$ of the critical current of the BSCCO tape under self-field (70 A at $77 \mathrm{~K}$ ). This clearly shows the degradation of the critical current which results from the increase of the magnetic field, everywhere in the coil, due to the neighbouring turns.

Furthermore, different studies have shown that the experimental U(I) curves are also sensitive to the deterioration of the HTS wire during the winding process. In fact, the tape is exposed to various mechanical, thermal and chemical stresses like bending, tension and welding $[9,10,11]$, from which a reduction of the critical current is expected. 


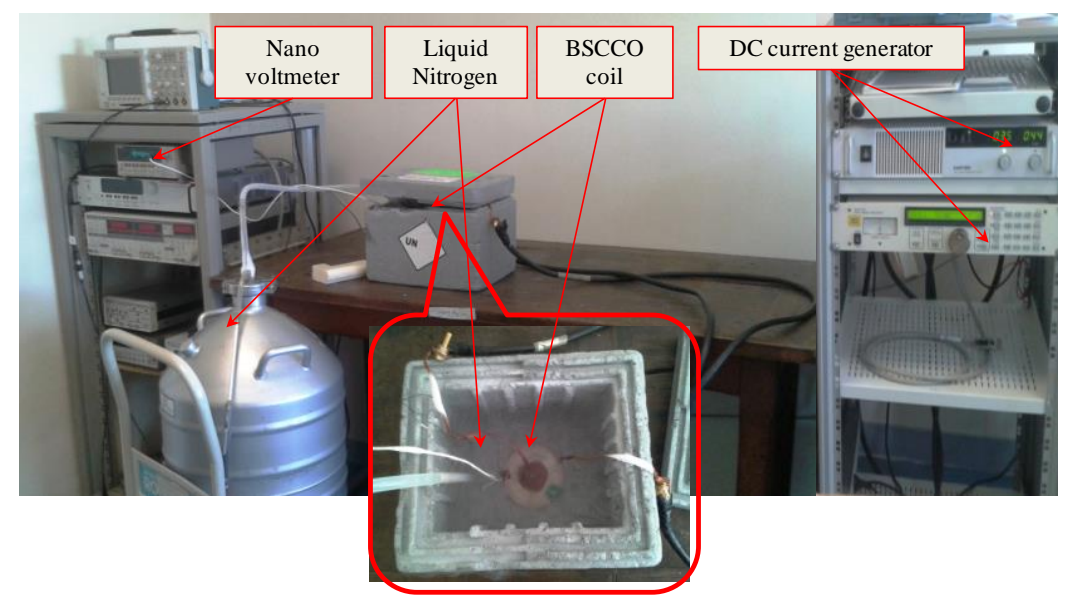

Figure 6 Photograph of the test bench for measuring the U(I) curve of the HTS coil

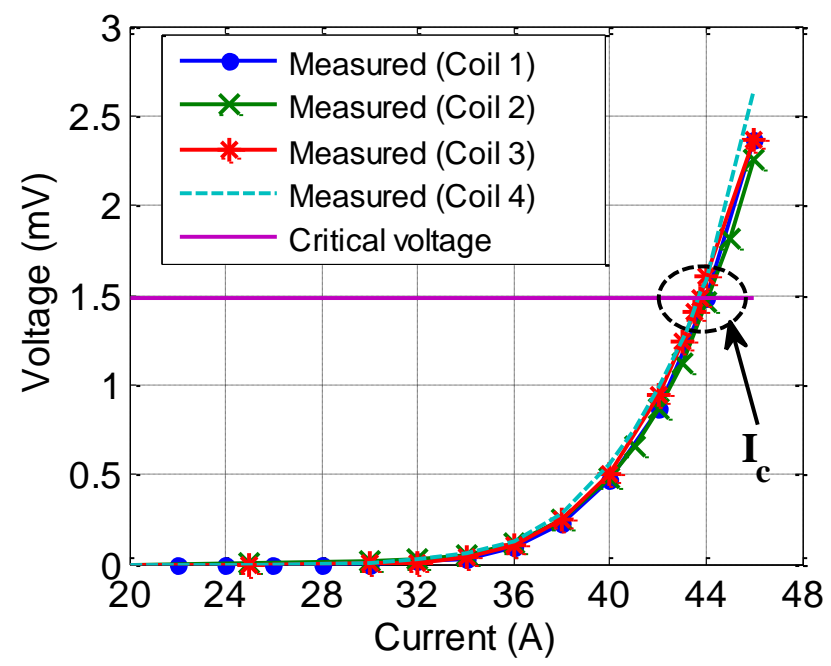

Figure 7 Measured U(I) curves of the manufactured coils.

The measured critical currents are: 44, 44, 43.8 and 43.7 A, respectively.

\subsection{Test of the HTS coils in the assembled coupler}

The same procedure as in section 4.1 is used here to determine the U(I) curve of the HTS coils. The coupler is fully assembled and the HTS rotor is immerged in liquid nitrogen inside the cryostat. This corresponds to the actual operating conditions of the HTS coils.

The AFSMC is considered to be at no load conditions (zero torque), this operating point-corresponds to a load angle $\delta=0^{\circ}$. The airgap, which includes the cryostat wall, is set to $9 \mathrm{~mm}$, Figure 8 .

The experimental U(I) curves of each coil are presented in Figure 9. Again, these voltage-current curves are similar which shows the integrity of the coils in the actual operating condition. 
The critical currents are 33.6, 34.6, 33.7 and 34.4 A respectively, which corresponds to an average value of $34 \mathrm{~A}$. This current is approximately $50 \%$ lower than the self-field critical current of the used BSCCO tape. This is obviously fully expected because the HTS tape is now submitted to the magnetic fields due to the neighbouring coils and the permanent magnets. Furthermore, the presence of the ferromagnetic materials influences the magnetic field distribution and consequently the critical current.

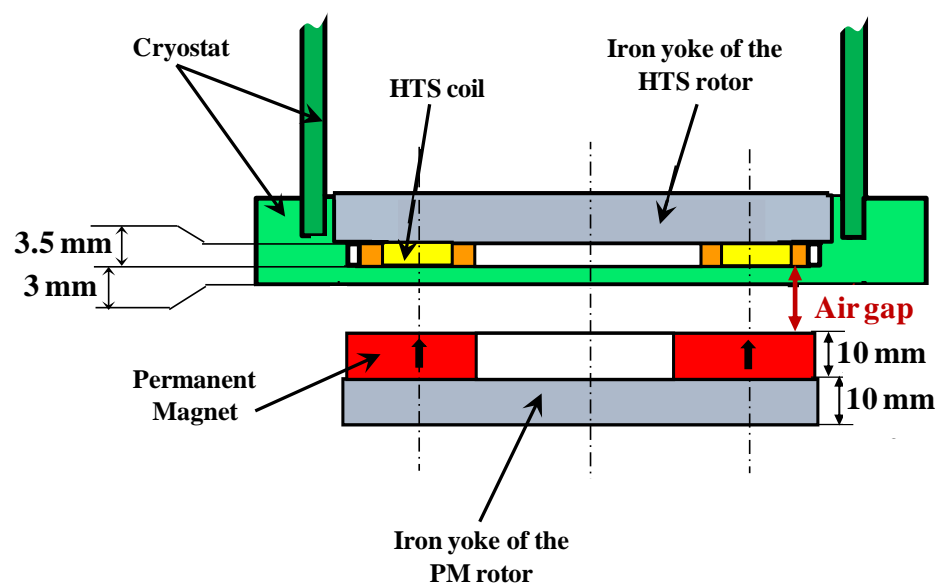

Figure 8 Schematic 2D view of the AFSMC under no-load condition $\left(\delta=0^{\circ}\right)$

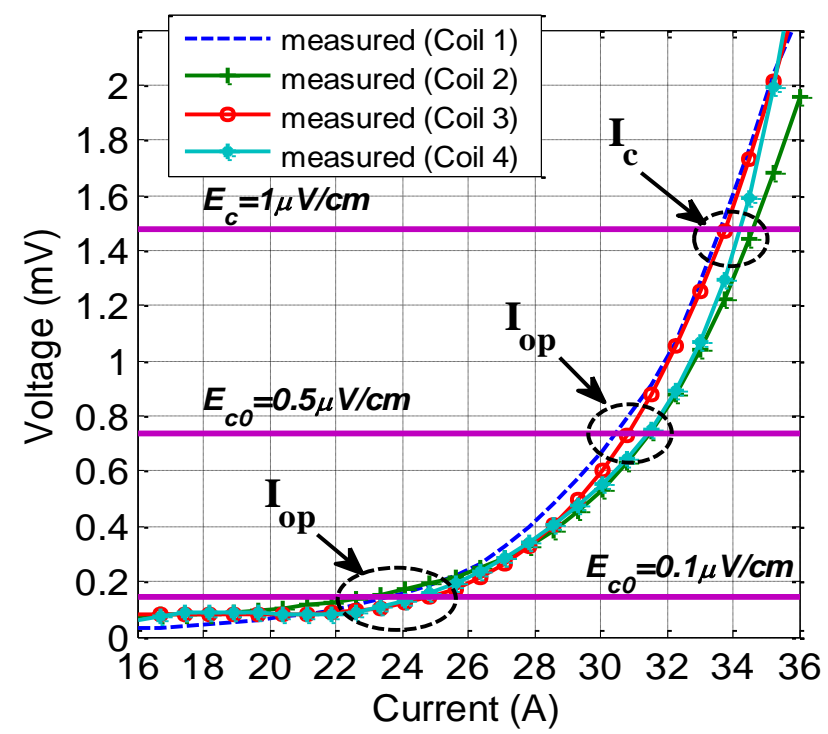

Figure 9 Measured U(I) curves of the assembled AFSMC for $\delta=0^{\circ}$. The measured critical currents $\mathrm{I}_{\mathrm{c}}$ corresponding to a critical electric field $E_{c}=1 \mu \mathrm{V} / \mathrm{cm}$ are: $33.6,34.6,33.7$ and $34.4 \mathrm{~A}$, respectively

\subsection{Operating current of the studied HTS coupler}

It is well known that HTS materials exhibit a non-linear relation between the electric field $E$ and the current density $J$. This non-linearity is well described by the power law [12]. The so called 'operating current' is defined as the maximal allowable current avoiding thermal limits. It depends on magnetic 
flux density components, cooling temperature and mechanical constraints [13, 14].

Several methods exist to determine the operating current of HTS devices. In this study, we have compared two methods. The first one is theoretical and based on the computation of the flux density distribution. The second one is fully experimental and based on the measured U(I) curves.

\section{a) Theoretical method for determining the operating current}

In this method, a "magnetic" operating point is computed. It is necessary to determine the flux density distribution in the HTS coil using the 3D FE model. The critical currents vs. flux density curves of the HTS tape (given by the manufacturer or measured by the end-user on a sample) are also needed. Because of the anisotropy of the BSCCO tapes, these curves are given for the perpendicular and the parallel components (to the widest face of the tape) of the flux density. Similarly, the method could be used if the $\mathrm{I}_{\mathrm{c}}(\mathrm{B}, \Psi)$ curve is available, $\Psi$ being the angle between $\vec{B}$ and the c-axis of the HTS tape [15].

For the studied device, the BSCCO tapes are disposed vertically along the $\mathrm{z}$ axis as shown in Figure 10. Hence, in a cylindrical coordinate system associated to the coil, the parallel and perpendicular flux densities are given by

$$
\begin{gathered}
B_{\perp}=\left|B_{r}\right| \\
B_{\|}=\sqrt{B_{z}^{2}+B_{\theta}^{2}}
\end{gathered}
$$

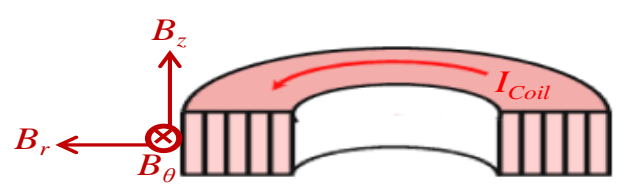

Figure $103 \mathrm{D}$ view of half a pancake coil showing the disposition of the BSCCO wires

The flux density on a given tape is not only due to the coil to which it belongs, but also to the neighbouring coils and the magnets. To determine the operating current of the coupler, we proceed as follows:

1- Set the load angle at a constant value (ie. $\delta=0^{\circ}$ at no-load and $\delta=45^{\circ}$ for pull-out torque)

2- Supply the HTS coils with a constant dc current value $\mathrm{I}_{\text {coil }}$

3- Compute by 3D FE the magnetic field distribution in the considered HTS coil and determine the maximum values of the parallel and the perpendicular flux densities $B_{\perp \max }$ and $B_{\| \max }$

4- Increase $\mathrm{I}_{\text {coil }}$ and repeat 2 and 3 until the desired current is reached (no more than the critical current of the tape under self-field) 
5- For each component of the flux density (viz. $B_{\perp}$ and $B_{\|}$), plot in the same figure the load curve $\mathrm{I}_{\text {coil }}\left(B_{\perp \max }\right.$ or $\left.B_{\| \max }\right)$ and the manufacturer's critical current vs. flux density curve $\mathrm{I}_{\mathrm{c}}\left(B_{\perp \max }\right.$ or $\left.B_{\| \max }\right)$.

The intersections of the curves give different values, from which the considered value of the operating current is the smallest one.

For the studied magnetic coupler with an airgap set to $9 \mathrm{~mm}$, Figure 11 presents the obtained curves for two values of the load angle $\delta=0^{\circ}$ (no-load) and $\delta=45^{\circ}$ (pull out torque). The $\mathrm{I}_{\mathrm{c}}(\mathrm{B})$ curves given by the manufacturer are obtained for a critical electric field criteria of $1 \mu \mathrm{V} / \mathrm{cm}$.

A particular shape is obtained for the load curve corresponding to the perpendicular field $B_{\perp}$ at $\delta=0^{\circ}$ (Figure 11.b). This curve is composed of two distinct line segments which intersect at (30A, 0.052T) approximatively. This intersection corresponds to a change of the coordinates of the point on which $B_{\perp}$ is maximal. This can be explained by the flux density plots of Figure 12 taken on a coil surface near the airgap (where $B_{\perp}$ presents the highest values). The first segment corresponds to current values ranging from 0 to approximately $30 \mathrm{~A}$ for which the maximum $B_{\mathrm{r}}$ value is located on the outer surface of the coil (near $\mathrm{R}_{\mathrm{be}}$ ). The second segment corresponds to currents above $30 \mathrm{~A}$, for which the maximum absolute value of $B_{\mathrm{r}}$ is located on the inner surface of the coil (near $\mathrm{R}_{\mathrm{bi}}$ ).

For the parallel field, the maximum operating current is about $22 \mathrm{~A}$ for $\delta=0^{\circ}$ and $25 \mathrm{~A}$ for $\delta=45^{\circ}$ (Figure 11.a). For the perpendicular field (Figure 11.b), these values become $31 \mathrm{~A}$ and $23 \mathrm{~A}$ respectively. Hence, the final value of the operating current is about $22 \mathrm{~A}$.

It can be clearly seen from the manufacturer's $\mathrm{I}_{\mathrm{c}}\left(B_{\perp}, B_{\|}\right)$curves that the perpendicular field has the most important influence on the critical current. However, the results show that the parallel field has a slightly higher influence than the perpendicular field in determining the operating current. This is particular to the studied coupler because the parallel field (0.6T), mainly due to the PMs, is much higher than the perpendicular field $(0.08 \mathrm{~T})$. 


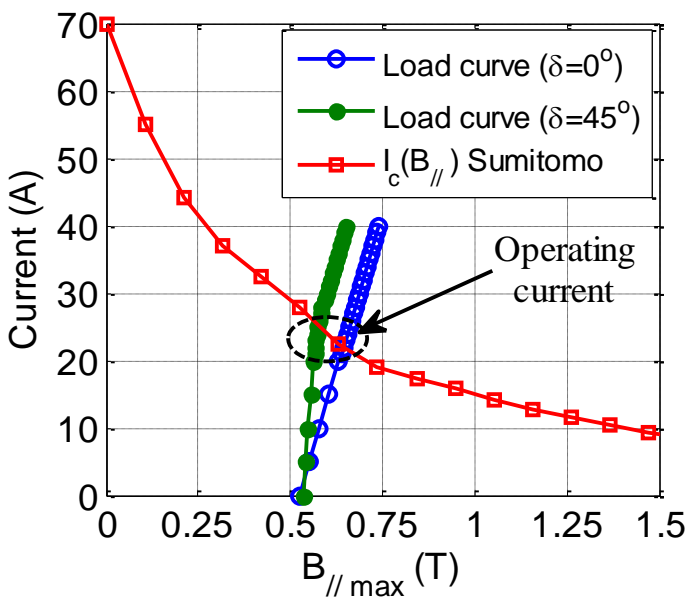

(a)

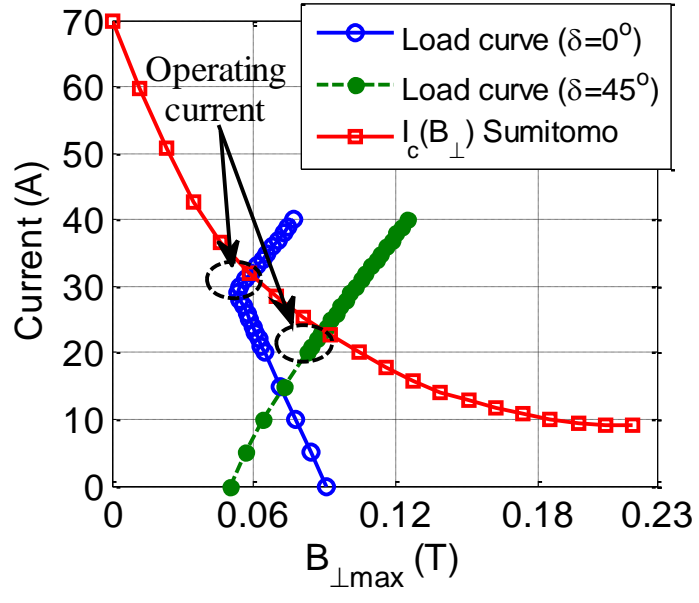

(b)

Figure 11 Operating current determination by load curves (a) parallel field $\mathrm{B}_{/ /}$(b) perpendicular field $\mathrm{B}_{\perp}$
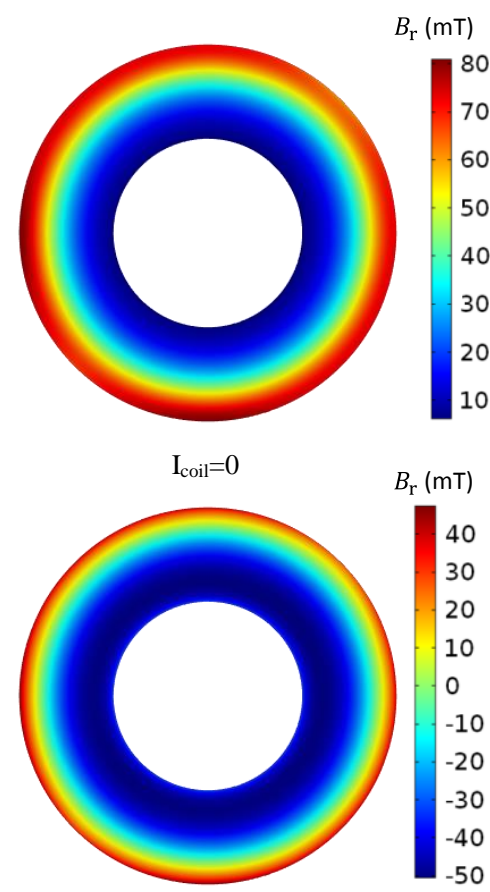

$\mathrm{I}_{\text {coil }}=31 \mathrm{~A}$
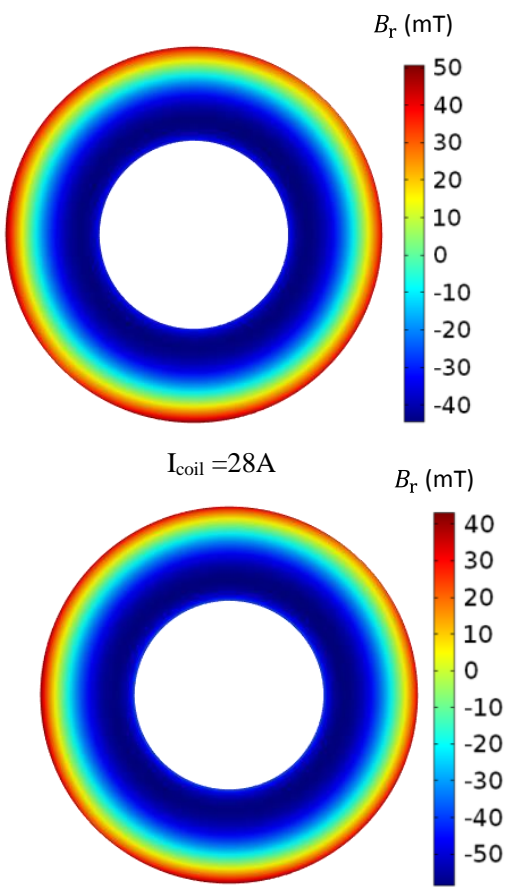

$\mathrm{I}_{\mathrm{coil}}=35 \mathrm{~A}$

Figure 12 Radial flux density $\left(\mathrm{B}_{\mathrm{r}}\right)$ distribution on a coil surface near the airgap for different current values

\section{b) Experimental technique for determining the operating current}

All what we need is the measured U(I) curves of the HTS coils given in Figure 9. As proposed in [16, $17,18]$, the operating current $\left(\mathrm{I}_{\mathrm{op}}\right)$ is defined by the intersection of the $\mathrm{U}(\mathrm{I})$ curve with the critical voltage line defined for an electric field value $\mathrm{Ec}_{0} \in[0.1-0.5] \mu \mathrm{V} / \mathrm{cm}$. These electric field values are used instead of the usual $\mathrm{E}_{\mathrm{c}}=1 \mu \mathrm{V} / \mathrm{cm}$ criteria to define the critical current. For $\mathrm{Ec}_{0}$ values of 0.1 and $0.5 \mu \mathrm{V} / \mathrm{cm}$, the 
critical voltage for the manufactured HTS coils is $0.148 \mathrm{mV}$ and $0.74 \mathrm{mV}$, respectively. Hence, using the U(I) curves of Figure 9, the operating current takes values of 23 and $31 \mathrm{~A}$.

The methods presented in a) and b) give almost the same operating current value, the lowest values being $23 \mathrm{~A}$ for the experimental technique and $22 \mathrm{~A}$ for the theoretical method.

Nevertheless, we have carried out several tests at operating current values up to $30 \mathrm{~A}$ without any problem. We choose in this paper to present the results for an operating current of 25A.

There is in general no precise rule to define an operating current. Indeed, the critical current is defined with an arbitrary criterion $\left(\mathrm{E}_{\mathrm{c}}=1 \mu \mathrm{V} / \mathrm{cm}\right)$ and it doesn't correspond to any critical situation for the HTS coils. Defining an operating current is then closely related to the considered HTS device, the cooling temperature and any specific operating condition. This important question is probably a matter of further investigations but this is beyond the scope of this paper.

\subsection{Flux density distribution}

The airgap flux density distribution has been measured and compared to the one calculated by 3D FE. The HTS coils have been supplied with an operating current of $25 \mathrm{~A}$. The load angle is set to $\delta=0^{\circ}$ (noload conditions). The air gap is fixed to $20 \mathrm{~mm}$ as to allow an easier insertion of a Hall probe. In fact, a Gaussmeter with a transverse Hall probe has been used to measure the flux density. Its sensitivity is about $1 \%$ in the interval $[0-3] \mathrm{T}$.

The $\mathrm{z}$-component $\left(\mathrm{B}_{\mathrm{z}}\right)$ of flux density has been computed and measured on a plane defined in the middle of the air gap. The measurements, which cover one pole (Figure 13), are obtained with a Hall probe whose position is controlled by an $\mathrm{x}, \mathrm{y}$ positioning table.

The numerical and the experimental results are shown in Figure 14. The maximum measured value of the flux density is about $0.45 \mathrm{~T}$ and the computed one is $0.41 \mathrm{~T}$ (a relative error of about $8.8 \%$ ).

For a better estimation of the difference between the numerical and the experimental results, we have performed the measurements of $B_{z}$ along a line crossing two poles as shown in Figure 15. Despite the error on the measured airgap value $( \pm 1 \mathrm{~mm})$ and the lack of precision on the Hall probe position, the computed and measured results are in satisfactory agreement, the relative error being smaller than $9 \%$.

We have also plotted in Figure 16 the flux density distribution on a vertical plane shown on Figure 16.a (it corresponds to the line shown in Figure 15). As it can be seen, the norm of the flux density in the iron yokes (Figure 16.b) is low enough to consider the material as linear. To provide more details about the field distribution in the HTS winding, the parallel and perpendicular components of the flux density are provided in Figure 16.c. For the perpendicular field component, one can see that the flux density maximal values are located on the coils surface in the airgap. The parallel flux density is homogeneous along the coils thickness; the highest values being located on the inner turns of the coil. 


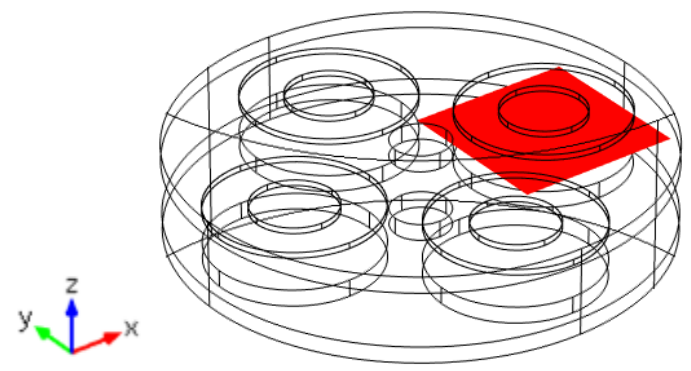

Figure 13 Surface in the middle of the air gap for the calculation of the flux density $\mathrm{B}_{\mathrm{z}}$ at no-load condition $\left(\delta=0^{\circ}\right)$

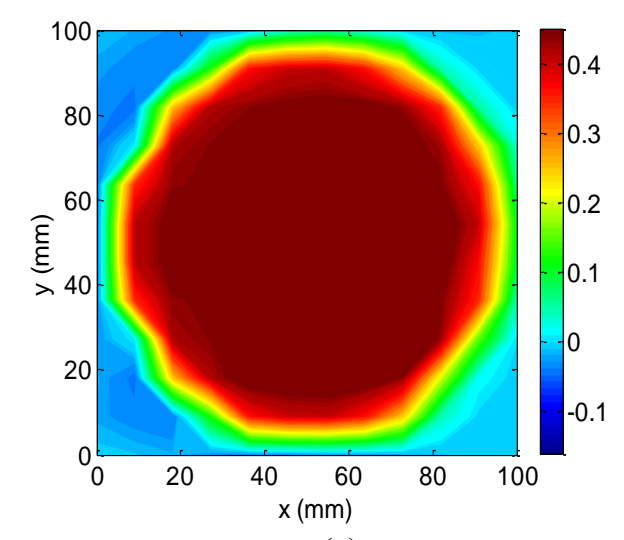

(a)

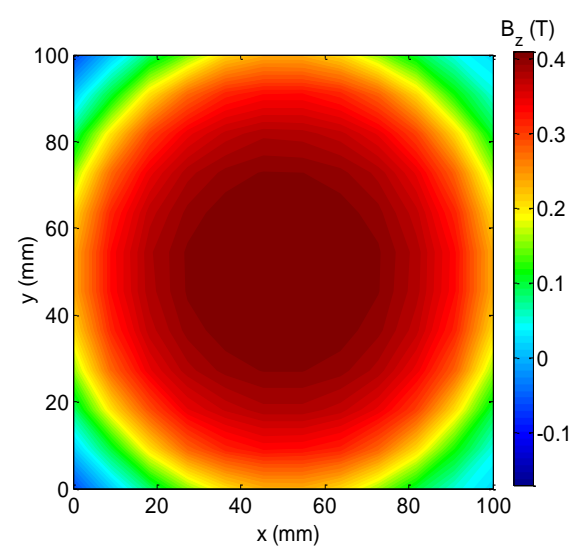

(b)

Figure 14 Distribution of the flux density $\mathrm{B}_{\mathrm{z}}$ over 1 pole at no-load condition $\left(\mathrm{I}=25 \mathrm{~A}\right.$ and $\left.\delta=0^{\circ}\right)$ (a) Experimental (b) 3D FE
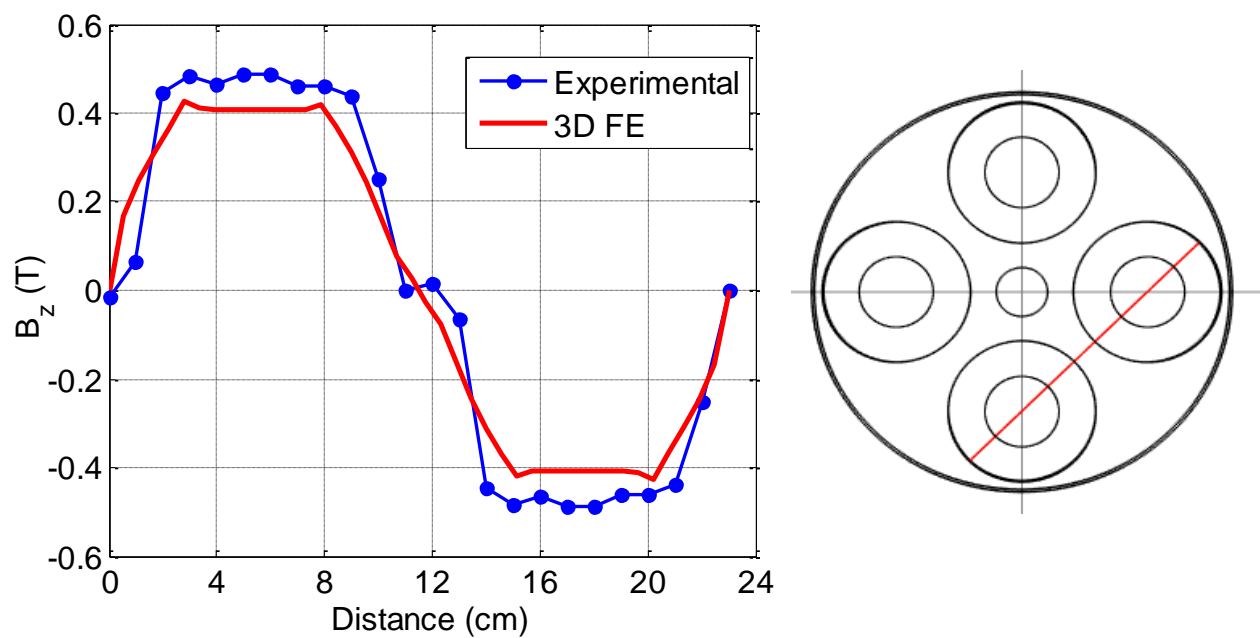

Figure 15 Flux density $B_{z}$ along a line crossing two coils in the middle of the airgap $\left(\mathrm{I}_{\text {coil }}=25\right.$ A and $\left.\delta=0^{\circ}\right)$ 


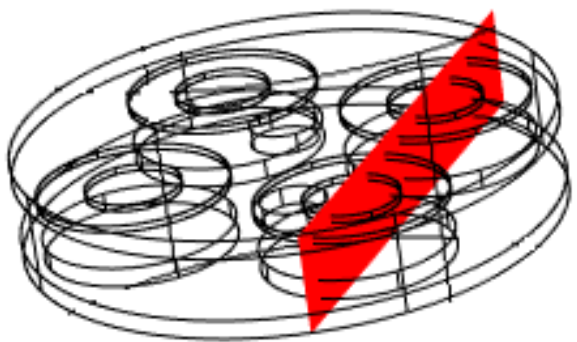

(a)

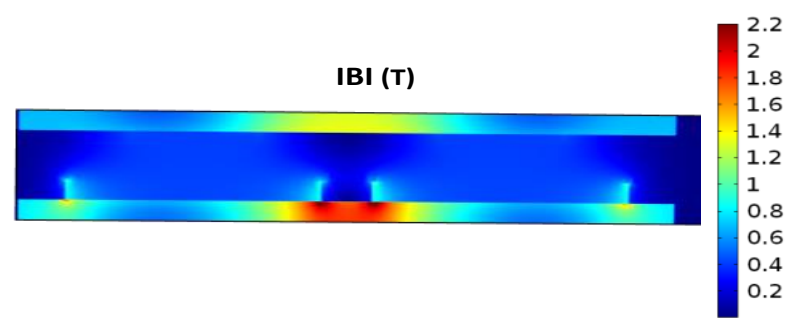

(b)
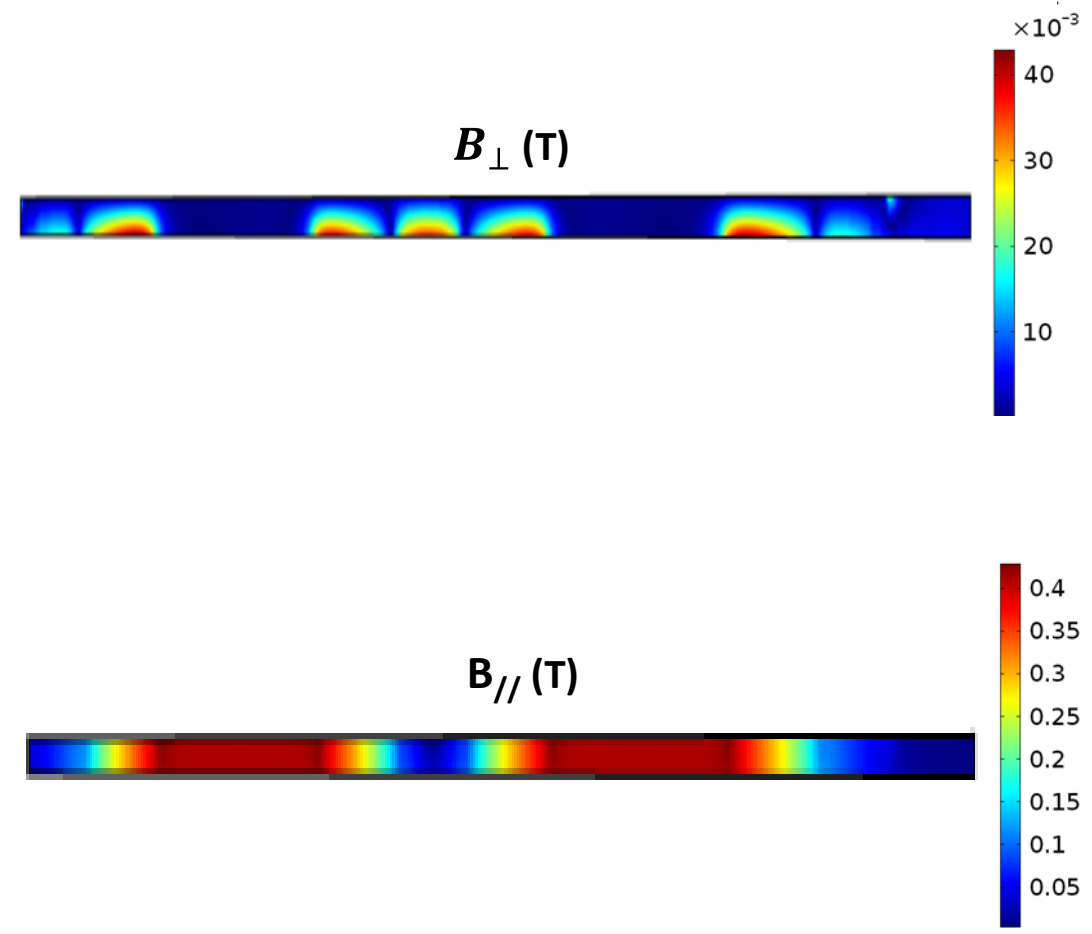

(c)

Figure 16 Flux density distributions along a vertical plane crossing two coils $\left(\mathrm{I}_{\text {coil }}=25 \mathrm{~A}\right.$ and $\left.\delta=0^{\circ}\right)$

(a) Computation plane (b) norm of B (c) perpendicular and parallel flux density on the coil

\subsection{Static Torque}

The static torque was measured by suspending weights attached to the end of a rope. The rope is attached to the lateral surface of the PMs rotor yoke through a pulley (Figure 17). The superconducting rotor is stationary and the PMs rotor angular position varies with the suspended weight. The displacement angle (load angle) has been measured by projecting, on a plane wall, a laser beam attached to the moving yoke. 
For the operating current of $25 \mathrm{~A}$, we have measured the static torque for airgap values of 9 and $20 \mathrm{~mm}$, respectively.

Figure 18 presents the measured and the computed static torque vs. load angle curves. It can be seen that for the airgap of $9 \mathrm{~mm}$, the 3D FE predictions give a pull-out torque of about $28 \mathrm{Nm}$ while the measurements give $33 \mathrm{Nm}$. The numerical model underestimates the pull out torque with a relative difference of about $9.7 \%$. For the airgap of $20 \mathrm{~mm}$, the measured and calculated pull-out torques are $19.6 \mathrm{Nm}$ and $16.3 \mathrm{Nm}$, respectively (16\% error).

These discrepancies between the computed and the measured torques may result from many origins related to the following aspects:

- Uncertainties in the measured airgap thickness

- Eccentricity due to imprecise positioning of the two rotors

- Static friction torque due to the "pulley-rope" system and to the angular-contact ball bearing used in the PM rotor. Of course, this friction torque increases with the very low temperature of the PMs rotor which is very close to the HTS rotor immerged in liquid nitrogen (weak thermal insulation through the airgap).

Nevertheless, the results are globally satisfactory and we believe that the main objective of this work has been achieved. Indeed, we learned a lot on the design, characterization, construction and testing of HTS devices.

The designed demonstrator has not a torque density which one could expect from the use of HTS. In a real application, the following actions could be taken to get higher torque/power densities:

- The HTS tape length we used is very low to produce high flux density in the airgap. Obviously, it will be necessary to increase this length to have better performance.

- Most of high torque density HTS electrical machines are cooled at $30 \mathrm{~K}$ using cryocoolers because the critical current of HTS tapes is higher. For example [6], the critical current of the H type BSCCO tape under a 1T applied perpendicular field is about 300A; which corresponds to 4-5 times the critical current of the BSCCO tape used in this paper. We can then expect at least 4 times more torque than what we get in this paper.

- In axial field machines, we usually use race-track coils instead of solenoids and sector PMs instead of disc PMs. Indeed, this leads to a more efficient utilisation of the active material (HTS and PMs) which results in higher airgap flux densities and higher torque transmission capabilities.

- Use $2 \mathrm{G}$ (Re-BCO) tapes to increase the operating current as $2 \mathrm{G}$ HTS performs better under high perpendicular field. 
- Finally, in a high power application, the HTS device will be bigger. However, the magnetic airgap will not increase a lot compared to the one used in our demonstrator $(10-20 \mathrm{~mm})$. In this case, compared to conventional topologies of magnetic couplers the gain in the torque/power density would be significant.

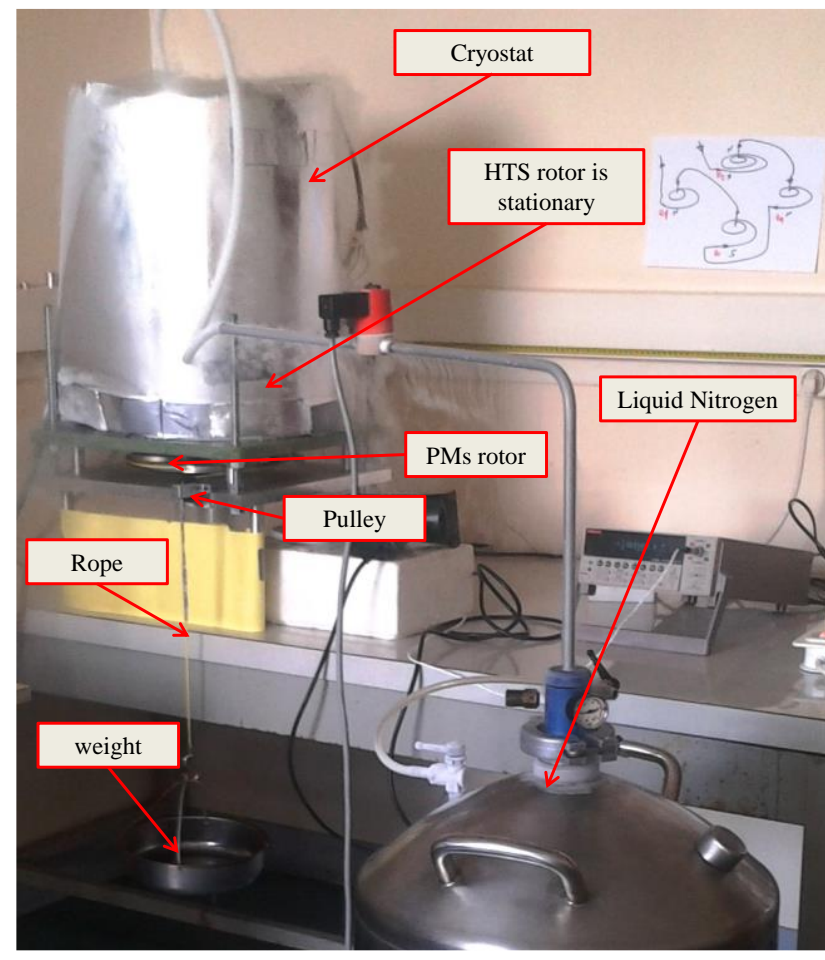

Figure 17 Photograph of the test bench for torque measurement

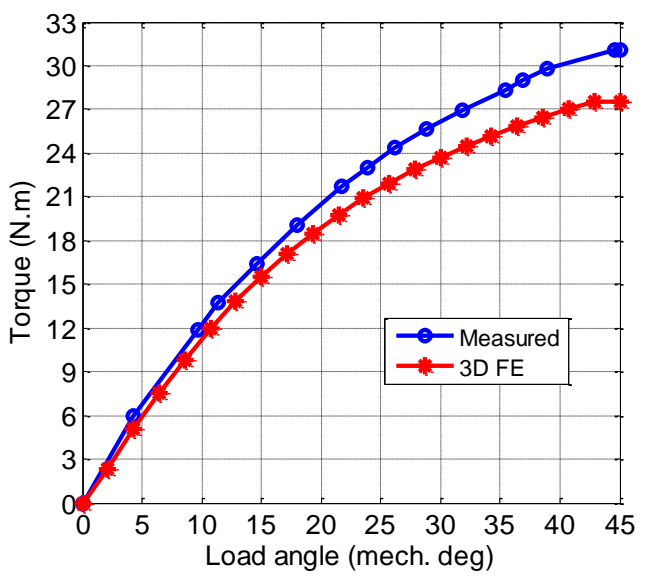

(a)

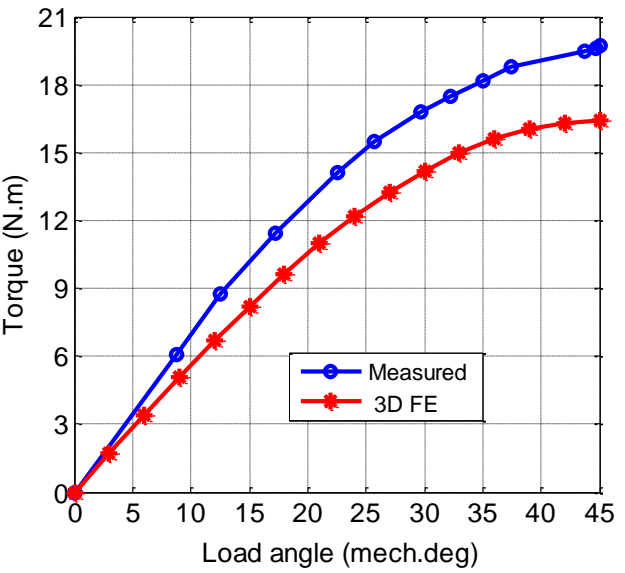

(b)

Figure 18 Static torque vs. load angle $\left(\mathrm{I}_{\text {coil }}=25 \mathrm{~A}\right)$

(a) airgap $=9 \mathrm{~mm}($ b) airgap $=20 \mathrm{~mm}$ 


\section{Conclusion}

We have presented in this paper the construction and tests of a HTS axial field magnetic coupler. This contactless torque transmitter can constitute an effective solution to replace the torque tube usually used in superconducting machines. Many construction details have been provided with a focus on the HTS coils fabrication and tests. The voltage-current curves of the HTS coils are almost the same which was of great importance for a good operation of the coupler.

A 3D finite element model has been developed to compute the magnetic field distribution and to estimate the AFSMC performances. The model has been used to determine the operating current of the coupler through the computation of a load curve. The results are found to be consistent with those issued from a fully experimental technique to determine the operating current.

Airgap magnetic field and torque measurements have been carried out and compared to the FE results. It has been shown that the measured and the computed quantities are in satisfactory agreement.

Further studies on HTS magnetic couplers are ongoing in order to optimize their design and construction. In future works, magnetic couplers will be designed to operate at 20-30 K which are the usual working temperatures for achieving high power/torque densities.

\section{Acknowledgements}

This work has been undertaken in the "Applied superconductivity in electrical engineering" group of the GREEN laboratory. The authors thank all the members of this group for their assistance in achieving this work.

\section{References}

[1] Cong. M, Li. T. 2008 15th International conference on Mechatronics and Machine Vision in Practice 346-351.

[2] Matsuzaki. H, Kimura. Y, Ohtani. I, Morita. E, Ogata. H, Izumi. M, Ida. T, Sugimoto. H, Miki. M, Kitano. M. 2006 Supercond. Sci. Technol 43 776-779

[3] Rezzoug. A, Mailfert. A, and Manfe P. 1984 IEEE Trans. Appl. Supercond. 20. 1795- 1797

[4] Belguerras L, Hadjout. L, Lubin. T, Mezani. S, Rezzoug. A 2014 IEEE Trans. Appl. Supercond. 243600912

[5] Kwon. W-S, Moon. T-S. Park. H-J, Kim. Y-Ch 2008 US Pattent 0100158A1

[6] Sumitomo Electric, http://global-sei.com/super/hts_e/type_ac.html

[7] Kitaguchi H, Takahashi K, Kumakura H, Hayashi T, Fujino K, Ayai N and Sato K 2009 Supercond. Sci. Technol. 220455005 
[8] Zhang D et al 2010 IEEE Trans. Appl. Supercond. 20764

[9] Yamazaki K, Kagiyama T, Kikuchi M, Yamade S, Nakashima T, Kobayashi S, Osabe G, Fujikami J, Hayashi K and Sato K 2012 Supercond. Sci. Technol. 25054015

[10] Gömöry. F, Klinčok. B 2006 Supercond. Sci. Technol. 19732

[11] Zhang. G. M, Schwartz. J, Sastry. P, Lin. L. Z, Xiao. L. Y, and Yu. Y. J 2004 Supercond. Sci. Technol. 171018

[12] Bruzzone. P 2004 Physica C Superconductivity 401 7-14

[13] Kiss. T, Noda. S, Nishimura. S, Ohya. K, Utsunomiya. D, Ilyn. Yu. A and Okamoto. H 2001 Physica C: Superconductivity 357-360 1165-1168

[14] Lee. J, Kwon. Y, Baik. S, Lee. E, Kim. Y, Moon. T, Park. H, Kwon. W, Hong. J, Park. M, Yu. I, and Jo. Y 2007 IEEE Trans. Appl., Supercond 17 1603-1606

[15] Sunwong P., Higgins J. S., and Hampshire D. P. 2010, Journal of Physics: Conference Series 234022013

[16] Pitel.J, 2013 Supercond. Sci. Technol. 26125002

[17] Yamaguchi M, Fukui S, Muta I and Nakamura T 2002 Physica C 372-376 1406-9

[18] A. Korpela, T. Kalliohaka, J. Lehtonen, R. Mikkonen, J. Pitel, and P. Kovac 2002 IEEE Trans. Appl. Supercond., 12 1438-144. 